\title{
Methoxyflurane analgesia for burns dressings
}

\author{
Kathleen J. Packer* \\ M.B., B.S., F.F.A., R.C.S. \\ Southampton Group of Hospitals
}

\begin{abstract}
Summary
The requirements for analgesia for burns dressings are discussed.

Methoxyflurane has proved satisfactory in a clinical trial, and can be administered by one of two types of vaporizer.

The possibility of nephrotoxicity due to methoxyflurane has not been eliminated.
\end{abstract}

THE terms 'burns dressing' and 'analgesia', as they are understood in the McIndoe Burns Unit at East Grinstead, will first be defined. Methoxyflurane as an analgesic for burns dressings will then be discussed.

The term 'burns dressing' may mean:

(1) Debridement and cleansing of the burn wound on admission, together with intravenous cannulation and urethral catheterization.

(2) Removal of old dressings and re-dressing of the burn wound.

(3) Minor desloughing procedures.

(4) Replacement of lyophilized skin by autograft.

(5) Immersion of the patient in a saline bath, during which time he may receive physiotherapy.

(6) In a small group of carefully selected patients, the taking of split thickness autograft.

These procedures are all painful and require analgesia. This means the complete, consistent and subjective control of the patient's pain. Anything less than this produces a frightened and apprehensive patient who loses confidence in his doctors and nurses. This in turn retards the ultimate aim of the Unit - to reduce the emotional trauma of the patient's burn and to return an economically independent individual to the community.

Any analgesic agent used for burns dressings must provide consistent, easily controlled levels of analgesia with no undue sedation. It should cause no cardiovascular or respiratory depression and no nausea or vomiting. It should not interfere with the patient's feeding pattern, since in the burnt patient, a feed missed is a feed lost. It should not interfere with the patient's emotional stability. In addition, if possible, repeated injections by the intravenous route should be avoided.

In December 1968, as a result of a request by

* Present address: Royal Hants County Hospital, Winchester.
Abbott Laboratories a small project to evaluate methoxyflurane as an analgesic for burns dressings was instituted. As a result of this project methoxyflurane is still the analgesic of choice in the McIndoe Burns Unit to-day.

\section{Methods of administration}

Two vaporizers have been used for the administration of methoxyflurane.

(1) The Analgizer is a disposable, draw-through vaporizer. It contains a polypropylene felt wick which acts both as a reservoir and vaporizing surface for approximately $15 \mathrm{ml}$ of methoxyflurane. It delivers from 0.3 to $0.8 \%$ methoxyflurane. Primarily designed for self-administration, it may either be held in the mouth or used with an anaesthetic face mask. The results of a clinical trial using this vaporizer were reported in 1969. The Analgizer is unavailable commercially in this country and an alternative vaporizer was sought.

(2) The Cyprane vaporizer is a temperature compensated, variable concentration draw-over vaporizer, calibrated from 0.1 to $1.0 \%$. Rebreathing through it is prevented by non-return valves. At first the results with this vaporizer were disappointing, especially with children, because the expiratory valve was inadequate for use in all positions, being partially gravity-sensitive. This problem was solved by substituting the Laerdahl anaesthesia valve, which is made of two types of plastic (one rigid for the body of the valve and one flexible for the moving parts). This valve is apparently not attacked by methoxyflurane over a large number of administrations and it can readily be dismantled for cleaning. The problem of cross-infection is completely eliminated by the Analgizer, which is individual to each patient. The Cyprane vaporizer and its tubing is being swabbed regularly, to try and assess and reduce the risks of cross-infection.

\section{Results}

Methoxyflurane has been administered on 406 consecutive occasions to eighty-eight patients. The age-range of the patients was from 4 months to 82 years, there being twenty-four patients aged under 5 years, thirteen aged between 5 and 10 years, thirteen between 10 and 20 years and thirty-eight 
over 20 years. The percentage body surface burnt ranged from 3 to $90 \%$. The average duration of administration was $45 \mathrm{~min}$, the shortest time being $15 \mathrm{~min}$ and the longest $2 \frac{1}{2} \mathrm{hr}$.

The patients were not starved before the dressing started and were allowed to eat or drink at any time during the dressing if they so wished. An anaesthetist was present at all dressings. After an initial explanation to the patient, methoxyflurane in air was administered at a concentration increasing to $0.9 \%$ for a full $10 \mathrm{~min}$ before the dressing was allowed to proceed. Once the dressing had started the concentration was then gradually reduced to between 0.3 and $0.5 \%$ depending on the patient's requirements. Administration was virtually continuous throughout the dressing. The anaesthetist kept a simple record of every administration, together with notes on the patient's response.

There has been a high degree of patient acceptance. A few have disliked the smell of the drug at first, but accepted it subsequently because of its analgesic properties. It was rejected completely in three patients, one a woman of 42 with a $30 \%$ burn who spoke no English and was too frightened to tolerate an anaesthetic mask. She received neuroleptanalgesia. A child of 8 with a $20 \%$ burn disliked the smell so much that neuroleptanalgesia was used after the first few dressings. He did not tolerate neuroleptanalgesia either because of the feeling of disorientation, so Ketalar was tried, but he disliked this too because of the unpleasant dreams. By this time he was healed. The third patient, a child of 10 , had fourteen dressings with methoxyflurane, being changed to neuroleptanalgesia half way through his illness because he did not like the smell. After two neuroleptanalgesics he asked to go back to methoxyflurane because he disliked the needle pricks more.

Vomiting was a problem in one patient, a woman of 24 with a $20 \%$ burn. She had nine dressings with methoxyflurane and was nauseated after the last two, but preferred to continue with it because of the degree of analgesia achieved.

There have been no untoward reactions nor any cardiovascular or respiratory depression and there has been no evidence of hepatotoxicity due to methoxyflurane.

The association of renal dysfunction with methoxyflurane has not yet been substantiated although it is obviously of great concern. We have not been able to measure the blood levels of methoxyflurane or its metabolites in our patients, but there has been no case of fatal renal failure among them. In three patients, each of whom have had methoxyflurane on seven occasions, there has been no evidence of polyuria, increase in serum sodium or blood urea.

Since every patient's subjective assessment of pain and discomfort differs and depends largely upon his own state of mind, it has sometimes been felt prudent to add supplementary analgesics or tranquillizers either intramuscularly before or intravenously during the dressing. This has been done on eighteen out of the 406 occasions. The drugs used have been papaveretum, phenoperidine, droperidol and diazepam. Supplementary drugs have not been necessary when the Cyprane vaporizer and Laerdahl valves have been used

Two effects of methoxyflurane have been noted. Firstly, its analgesic properties and secondly, its mood-modifying effect. This latter takes the form of sedation, dissociation from the surroundings or amnesia. Our patients have all been fully alert and able to eat or drink within $15 \mathrm{~min}$ of the end of the dressing, but many have exhibited up to $30 \mathrm{~min}$ postoperative analgesia with complete retrograde amnesia.

\section{Conclusion}

In conclusion, therefore, it is our experience that methoxyflurane comes close to fulfilling all our criteria for an analgesic for burns dressings. However, since we have been using it there have been a disturbing number of reports of its nephrotoxic effects and therefore judgement on its final place in the treatment of burns must wait until this situation is clarified.

\section{Acknowledgments}

I am grateful to Dr R. M. Davies and the staff of the McIndoe Burns Unit for their advice and encouragement, to Dr M. B. Yorston for his help in the preparation of this article, to Abbott Laboratories for providing the vaporizers and to the photographic department at East Grinstead for providing the slides and film with which this paper was illustrated.

\section{References}

Artusio, J.F. JR., Van Poznak, A., Hunt, R.F., Tiers, F.M. \& Alexander, M. (1960) A clinical evaluation of methoxyflurane in man. Anesthesiology, 21, 512.

Committee on ANaesthesia, National Academy of Sciences-National Research Council (1971) Statement regarding the role of methoxyflurane in the production of renal dysfunction. Anesthesiology, 34, 505.

Dragon, A. \& GoldsteIn, I. (1967) Methoxyflurane: preliminary report on analgesic and mood-modifying properties in dentistry. Journal of the American Dental Association, 75, 1176.

LAIRD, S.M. \& GRAY, B.M. (1971) Intermittent inhalation of methoxyflurane and trichloroethylene as analgesics in burns dressings procedures. British Journal of Anaesthesia, 43, 149.

PACKer, K.J. \& Titel, J.H. (1969) Methoxyflurane analgesia for burns dressings: Experience with the Analgizer. British Journal of Anaesthesia, 41, 1080.

Sutherland, ANNE B. (1955) The nutritional care of the burned patient. British Journal of Plastic Surgery, 8, 68.

Sutherland, ANNe B. (1968). The problem of nutrition in the burned patient. Clinical Aspects of Burns. A Symposium. (Ed. M. Derganc), pp. 77-85. Published by The Organising Committee of the Third Yugoslav Congress for Plastic and Maxillofacial Surgery. 


\section{Discussion}

DR LAIRD (Chepstow): Do you change the rubber tubing between the vaporizer and the patient between each dressing?

DR PACKer: No, this is not done, but the mask remains individual to each patient and is thrown away when the patient is discharged.

DR LAIRD: Methoxyflurane is soluble in rubber, and we have found at Chepstow that we do not change the tubing and as the morning proceeds the analgesia becomes more effective.

Dr A. J. Gray (Preston): I would like to ask Dr Packer when the nausea came on in the case of the girl who did not like it. Was it at the beginning or was it at the end?

DR PACKER: It was towards the end, and this was most marked after the dressing. She would go through the dressing, and towards the end she would begin to feel sick. Back in her bedroom she would feel nausea for perhaps an hour or so afterwards.

Dr Russell M. Davies: As a matter of interest, on the subject of nausea, one patient is still under treatment in the hospital, and yesterday had her seventeenth Penthrane analgesia. The dressing on that occasion lasted $55 \mathrm{~min}$. For about the last eight dressings that she has had when the mask is applied to her face she retches, but she retches before methoxyflurane is delivered and after one or two heaves in fact settles down quite happily. She is not vomiting.

DR P. Baskett (Bristol): Dr Packer mentioned that she sometimes uses self-administration. Could she say on what percentage of occasions she finds this possible, keeping proper analgesia?

DR PACKeR: I cannot give you the figures for that. This has been done mainly with the Analgizer. With the variable concentration somebody has to twiddle a knob, but with the Analgizer there is a small hole in the bottom for the patient to put his finger over if he wants a bit more and he lets his finger off if he wants a bit less. Probably the percentage is quite low-something of the order, I would think, of $15 \%$. This is largely because we get, besides big burns, special burns. Many of these patients have burnt hands and, therefore, cannot hold it themselves anyway. The other group includes elderly patients who really cannot do this for themselves either. So, in fact, the percentage holding it themselves is quite low.

DR C. HutTer (Derby): How mentally alert do these patients remain when dealing with these concentrations?

DR PACKeR: This is very variable. Most of them are able to co-operate. Because of the nature of the burns and so on, if you say 'Lift up your leg' they cannot hold their leg up. They have to be helped. But most of them can co-operate. Obviously, this does not apply to the under5 -year-olds.

DR HUTTER: But they do not go off to sleep?

DR PACKER: Some of them do, yes.

DR S. FIRN (Sheffield): I have found that the children become too drowsy and we have lost their co-operation, possibly because I was keeping the concentration high. Do you just use the high concentration for the initial 10 $\min$ ?
DR PACKer: Yes, we give them a blast to start with, almost as an induction, and then reduce it down, and we turn it up a bit if we anticipate something particularly painful being done.

DR G. H. BusH (Liverpool): May I ask the reasons for the administrations of the other drugs which were given? Also may I take it that the results in all these cases have been to your entire satisfaction and to the patients' satisfaction? I presume that in your classification of analgesia you aimed to have these particular definite criteria, and may I assume that these were all satisfied?

DR PACKER: The supplementary drugs were given when we felt, to put it colloquially, that the patients were a bit 'twitched'. We had six Indian patients who were in an aeroplane which fell out of the sky. Many of the supplementary drugs were given to these patients. This was partly because of language difficulties and partly because it was early in the series and we were very much feeling our way. We did not have quite the confidence in the methoxyflurane which we had later in the series. In fact, most of these drugs have been given to the patient right at the beginning. It was really depression, anxiety and the feeling that probably a particular dressing was going to be a bit more painful than some of the others had been.

QUESTION: Was the whole thing satisfactory?

DR BUSH: Whether it came up to your criterion.

DR PACKER: Obviously not. You cannot be perfect all the time. But certainly it has been acceptable, I should think about $90 \%$ of the time. There have been a few cases where one has felt that it was not quite so good. I think that quite often it depends a bit on how the anaesthetist is feeling that particular day, too. Perhaps one is not so patient with the person receiving the methoxyflurane and one is a bit sharp, and you do not get quite such a good result. I think that part of the technique is talking to the patient during the dressing and saying 'It is all right. This is going well. You are doing all right'.

By and large, we have been happy and our patients have been happy, with little ups and downs in between times.

DR J. Pelmore (Bristol): I had the pleasure of watching you do one of these, and it seemed to me that you had to spend a lot of time with the patient and talking and that this was a very important part of the sequence. Does this not use anaesthetic strength in the hospital to a very marked degree, and are we not running into the risk of every dressing and every difficult condition for which patients are treated needing a separate anaesthetist to control the situation?

Dr PACKer: I am going to ask Dr Russell Davies to answer that question for me.

Dr Russell M. Davies: On the first point, yes it is heavy on manpower. If you work out 406 administrations with an average of $45 \mathrm{~min}$ each, it is something over 300 $\mathrm{hr}$ of anaesthetists' time. We accept this.

When the unit was planned we went to the Regional Board and asked for additional manpower in the Department from the Regional Board and this was granted. As a result of this, one full-time anaesthetist works wholetime in the Burns Centre and has no other duties in the 
hospital. Of course, they do other things beyond analgesia. They give all the anaesthetics. The Unit has its own theatre. They look after drips. They help with the biochemistry, do simple blood investigations and so forth. So one anaesthetist is confined there-if that is the word-at all times.

In reply to the question whether this is necessary or desirable, I think it depends on how much one believes in the criteria which we try to follow. We believe very deeply that if one sets out to control pain in the burnt patient, one should control it always, because the patient then has at least an understandable and expected pattern against which he can expect to have his dressings. So to this extent we would regard it as inevitable that it requires a lot of attendant time.

Going on and theorizing still further, whether in years to come the technique, if it persists, becomes so well established and so well defined for, for example, a nurse to look after the patient for much of the analgesia is a matter on which I would not at this point wish to speculate. It is, of course, something which we have turned over in our minds, but it is something that we have not done up to this point.

DR LAIRD: At Chepstow all our analgesias are selfadministered with the nurse carrying out the dressing supervising the proceeding. I will not pretend that our results are anything like as good as can be obtained with an anaesthetist present and supervizing, but it is quite satisfactory and has made a tremendous difference to the morale in the Burns Unit both among patients and among the nursing staff.

QUESTION: What vaporizer, what equipment, do you use for self-administration? This would be our problemmanpower.

DR LAIRD: Initially we used a Cardiff inhaler. We are now using the same vaporizer as here, the Pentec, fixed at $0.5 \%$. The valve we use is a disposable valve manufactured from the Analgizer. It is just a flat valve. This is quite a light piece of apparatus and even patients whose hands are burnt can hold the valve and mouthpiece between their teeth and obtain inhalation in that way.

DR R. BURTLEs (Edinburgh): We also use a Cardiff inhaler for the dressings which are done in the ward dressing room as opposed to the theatre. It has not yet spread that far. But using it under these conditions, we allow the sister of the ward or one of the more permanent staff nurses to do this, with the house surgeon present and an anaesthetist 10 or 15 yards away in the theatre. This question of anaesthetic manpower is a very real problem, and this is one way in which we feel we can help. The Cardiff inhaler being non-adjustable and approved for use by midwives in England and Wales, we feel that this is a reasonable arrangement. With children it has largely become self-administered. They soon catch on and, in fact, they look for it.

DR PACKer: This has been our experience, too.

DR BURTLES: They almost seem to get addicted to it.

DR ENDERBY (East Grinstead): As there has been some mention of nausea and vomiting, would you tell us what precautions you take with regard to feeding patients?

DR PACKer: We do not take any precautions with regard to feeding patients. We do not starve them beforehand and we are prepared to let them eat and drink during dressings if they wish to. We do have a sucker and all the equipment for resuscitation in the dressing room.

DR ENDERBY: Do you have any anxious moments?

DR PACKer: No, we have had no anxious moments, and no patient has actually vomited.

DR M. Beveridge (Aberdeen): Have you found it necessary to treat these?

DR PACKer: Yes, in fact in the case of one girl, we covered with, I think, perphenazine. We were giving this intramuscularly beforehand and finding that she needed something else afterwards as well.

DR W. N. Rollason (Aberdeen): You mentioned that there was a significance of hallucinations from Ketalar. What incidence have you found in children? I have only been using Ketalar for the past year and I have not a large number of patients, but so far we have not found this any problem at all.

DR PACKer: I mentioned Ketalar only in respect of one patient who had it on one occasion, and he did not like it. He got very unpleasant dreams. He described them as 'nasty dreams'. So I cannot comment beyond that.

DR ROLLASON: How old was this child?

DR PACKer: Eight.

Dr Russell M. Davies: In fact, since Dr Packer left, this experience has been repeated. I hope this will come out in discussion, possibly on a later paper. I do not wish to start a deep discussion on the relative virtues or vices of different drugs, but in using Ketalar one inevitably compares it with something, and you have to consider what you are comparing it with. I hope that we can possibly touch on that when we come to the subject.

Dr LuXMOore (Portsmouth): There are two points that I did not quite get. First, could you elaborate a bit on the amount of consciousness that is actually present in the patients and how often you have to talk to them and whether you have to chat right the way through on points of detail? Secondly, when you were doing the smaller children, what detailed modifications, if any, did you make in your circuit when you were using the draw-over inhaler to make it more suitable for tiny ones?

DR PACKER: The amount of chatting varied very much from patient to patient. One tends to talk to them most of the time during the $10 \mathrm{~min}$ induction period. One is not aiming at anaesthesia but rather at the nebulous inbetween stage when they are a bit sleepy but still have a cough reflex and can still swallow and reply to questions and lift their hands and so on when they are asked to. It is a fairly long time $-45 \mathrm{~min}$, with people stripping things off arms and legs. We would say 'We are coming along quite nicely. We have not much more to do. We have finished with this leg'-this sort of thing; really general encouragement and reassurance. With some of the older children one found that telling stories provided a bit of distraction from what was going on and, in fact, enabled one to run them on lower concentrations.

Dr Russell M. Davies: Might I add one word of amplification to the first part of that answer? During dressing, if a limb is going to be lifted-for example, a leg - the patient is always told which leg is being lifted and is asked to help. Quite definitely one can feel the weight go off one's hand when one goes to lift it. If any part which is going to be dressed is moved, the patient is told before. 
DR LUXMOORE: I wonder whether there is much noise from the surgical end.

Dr Russell M. Davies: No.

DR LuXMOORE: Because it might be necessary to plug the patient's ears with cotton wool.

DR PACKer: No.
QUESTION: Are there any difficulties about turning the patient over for dressing?

DR PACKER: Not really. It is a question of manpower again, for lifting them.

Dr Russell M. Davies: We tend to turn them a little past the $90^{\circ}$ and if we have to dress the other side we turn them back over the $90^{\circ}$ the other way. 